Original Research Article

\title{
Interns perception towards Pharmacology during clinical postings at RIMS, Raichur, India
}

\author{
Neeta T. Gavimath ${ }^{1}$, Vasant R. Chavan ${ }^{1}$, Rohit Dixit ${ }^{2 *}$
}

${ }^{1}$ Department of Pharmacology, Raichur Institute of Medical Sciences, Raichur, Karnataka, India

${ }^{2}$ Department of Pharmacology, SVS Medical College, Mahabubnagar, Telangana, India

Received: 22 January 2019 Accepted: 29 January 2019

\section{*Correspondence to:}

Dr. Rohit Dixit,

Email: rohitdixit.mbbsmd@ gmail.com

Copyright: (C) the author(s), publisher and licensee Medip Academy. This is an openaccess article distributed under the terms of the Creative Commons Attribution NonCommercial License, which permits unrestricted noncommercial use, distribution, and reproduction in any medium, provided the original work is properly cited.

\begin{abstract}
Background: Every medical graduate must have the intention to prescribe rationally. It is pharmacology which teaches rational of prescribing of drug in undergraduate medical course. Therefore, many eminent medical educationists believe that pharmacology is the most essential part of the medical curriculum. Medical graduates join as interns in their respective teaching hospital immediately after graduation. Although interns work is usually under the supervision of a senior consultant but there are occasions, when they need to make their own decision. Internship is the intermediate period between undergraduation and general practice. The dexterity of health professional relies upon prescribing practices. Clinical pharmacology and therapeutics (CPT) is a crucial discipline for interns to acquire safe and rational prescription of drugs. This study was conducted with the intention to provide some light about the knowledge of pharmacology among the interns in RIMS Hospital Raichur, Karnataka.

Methods: The study was done on interns of RIMS, Raichur. It was a descriptive questionnaire-based prospective study. A structured questionnaire modified from the work of Oshikoya et al, was used in the study which included four major categories namely basic demographic information, undergraduate CPT teaching, experience of adverse drug reaction (ADR) and any deficiency in the undergraduate CPT teaching.
\end{abstract}

Results: Out of these 107 participants 54 (42\%) rated pharmacology knowledge is good, while another 53(40\%) had average understanding. As high as $80 \%$ (85) intern population feel that undergraduate training has prepared them to prescribe safely. $45(41 \%)$ interns have already observed cases of adverse drug reactions in their short active clinical life.

Conclusions: The present study has identified that pharmacology and therapeutics course curriculum is not enough to produce safe prescribers.

Keywords: Clinical pharmacology and therapeutics, Interns, Medical education, MBBS, Questionnaire

\section{INTRODUCTION}

Pharmacology is one of the essential components in clinical practice. Prescribing correct therapy is the essential part of physicians and therefore, adequate knowledge on drugs' efficacy, safety, cost, and convenience is important. ${ }^{1}$ Lessons in Pharmacology provide and enrich medical students' knowledge and skill about different drugs and their utility in various diseases. ${ }^{2}$ The important goal in teaching of undergraduate students in pharmacology is to inculcate a rational and scientific basis of therapeutics. Clinical Pharmacology and Therapeutics (CPT) is a crucial discipline to acquire these competencies. Cultivating sound knowledge about CPT in under graduation and internship is, henceforth, compulsory. Hence the Indian government has progressively integrated CPT into undergraduate curriculum. $^{1}$

Integrated teaching method includes teaching in organ system based manner rather than didactic lectures. The benefits are widely discussed by WHO. ${ }^{3}$ 
Fresh medical graduates very often need to prescribe many times a day. Every medical doctor needs to develop the skill to select the right medicine for any disease from a very wide range of therapeutic choices. ${ }^{4}$ Pharmacology should be taught aiming to produce future rational prescriber. Erroneous choice of drug is one of the top medical errors and as high as $2 \%$ of all hospital admission in USA is due to 'medication errors' with majority of paediatric patients. ${ }^{5-8}$

Medical error results in 44,000-98,000 unnecessary deaths each year and 1,000,000 excess injuries in the United States of America. ${ }^{9}$ Again these mistakes and faults are mostly due to poor prescribing skill.,10 Inadequate prescribing knowledge and skill in the both developed and developing countries are also reported in numerous published articles. ${ }^{11-18}$

According to Medical Council of India (MCI), under "Regulations of graduate medical education", 1997, Medicinae Baccalaureus, Baccalaureus Chirurgiae (MBBS) is a certified study extending over four and half academic years divided into nine semesters followed by one year Compulsory Rotatory Residential Internship (CRRI). The period of four and half years is divided into three phases;

Phase-1 (2 semesters) which includes pre-clinical subjects viz Human Anatomy, Physiology, Biochemistry and introduction to Community Medicine including Humanitics;

Phase -2 (3 semesters) consisting of Para-clinical / clinical subjects viz Pathology, Pharmacology, Microbiology, Forensic Medicine including Toxicology and part of Community Medicine;

Phase-3 consists of continuation of study of clinical subjects for 7 semesters after passing phase- 1 and the clinical subjects are medicine and its allied specialities, surgery and its allied specialities, Obstetrics and Gynecology and community medicine.

No student shall be permitted to join phase-2 group of subjects until passing all the phase- 1 subjects. Overall didactic lectures were allotted one third of time schedule whereas two-third for practical, clinical or/ and group discussion.

\section{METHODS}

The study was conducted in a tertiary care hospital, Raichur, Karnataka, India. As a tertiary care hospital, the health care services offered are comprehensive covering investigation, diagnosis, therapy, surgery and postoperative care. The in-patient services are complemented with day centers, outpatient facilities. It teaches both under-graduate and post- graduate students. This study was conducted after obtaining approval from Institutional Ethical Committee.

\section{Development of questionnaire}

It was a descriptive questionnaire-based prospective study. A structured questionnaire modified from the work of Oshikoya et al, was used in the study which included four major categories namely basic demographic information, undergraduate CPT teaching, experience of adverse drug reaction (ADR) and any deficiency in the under-graduate CPT teaching. ${ }^{8}$ There were 22 questions which were mostly yes/ no type or multiple choice types. In multiple choices, more than one choice was allowed to be chosen. Fill in the blank type questions were also included.

\section{Participants}

The participants were interns of the college from first and supplementary batch. The study was conducted from February 2018 to July 2018. The interns were either in the end or middle of their internship. A total of 107 interns participated in the study. Informed written consent was obtained prior to their participation in the study. The questionnaire was filled on the spot. Confidentiality was assured.

\section{Statistical analysis}

Data were entered and analyzed using SPSS software (SPSS v16.0). The data were expressed through descriptive statistics.

\section{RESULTS}

Out of 107 respondents, 53\% were male and $47 \%$ were female out of which $64 \%$ were 22 years old, whereas $35 \%$ and $1 \%$ were 23 and 24 years old respectively. $81 \%$ of interns were aware of CPT which was taught during undergraduate period, whereas $19 \%$ were not aware of CPT. $56 \%$ of interns were satisfied with undergraduate CPT teaching and $44 \%$ were not satisfied as shown in Figure 1.

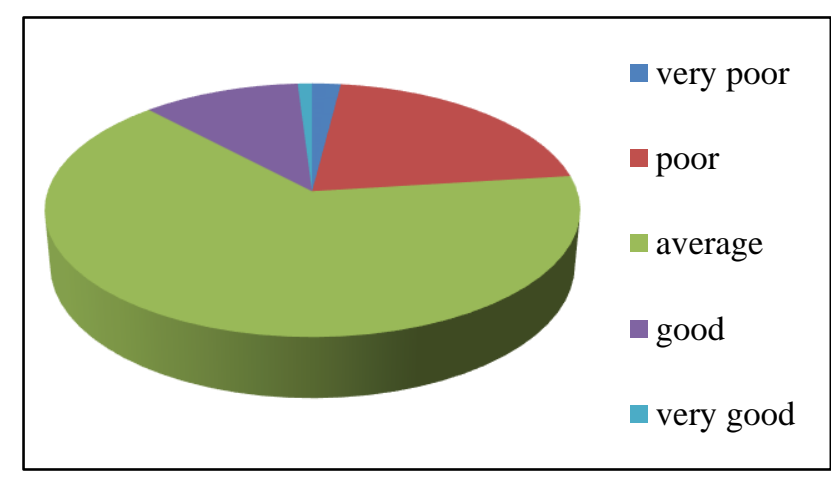

Figure 1: Knowledge about clinical pharmacology and therapeutics in percentage.

Among the respondents, 51\% of interns considered themselves capable of rational prescription, whereas $45 \%$ were not. $74 \%$ of participants had encountered problem while prescribing the drugs during their internship period 
whereas $31 \%$ were not. The various problems encountered during the internship by the interns while prescribing is shown in Figure $2.76 \%$ felt that experience is needed for prescribing; $47 \%$ and $31 \%$ felt that confidence and availability of advice and reference will improve prescribing ability.

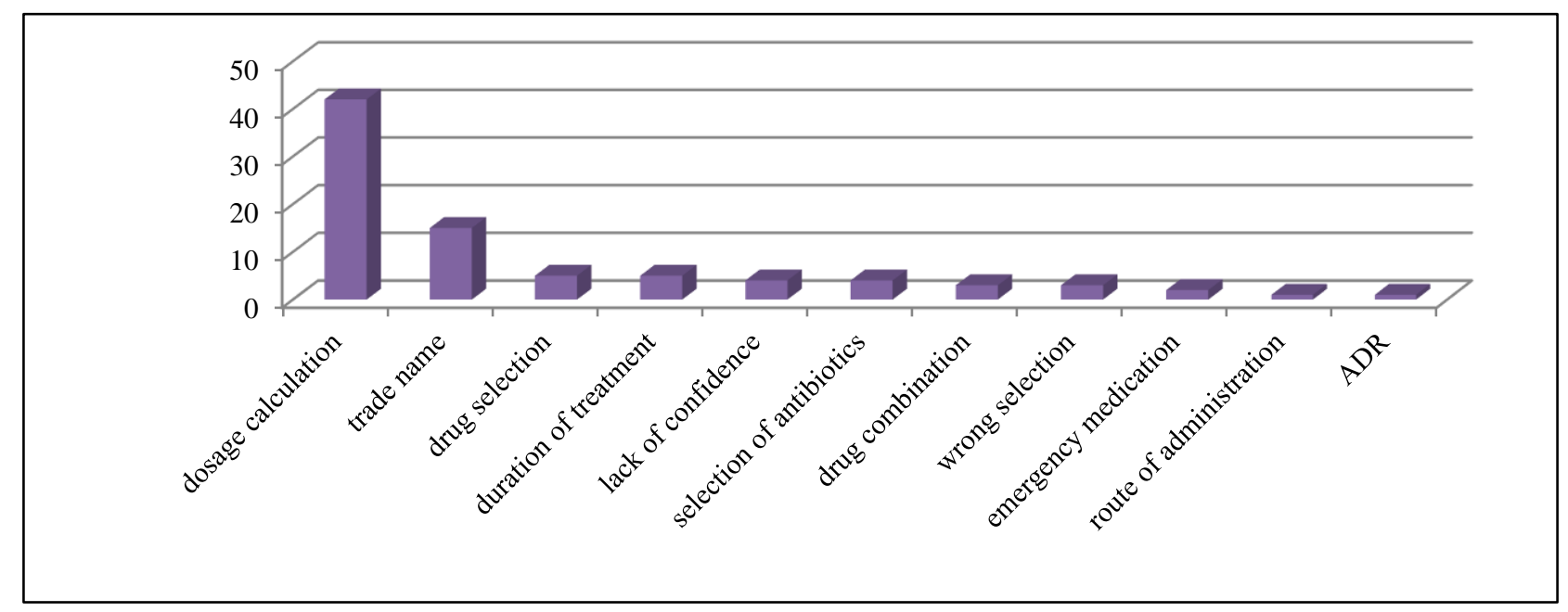

Figure 2: Problems encountered while prescribing during internship represented in percentage.

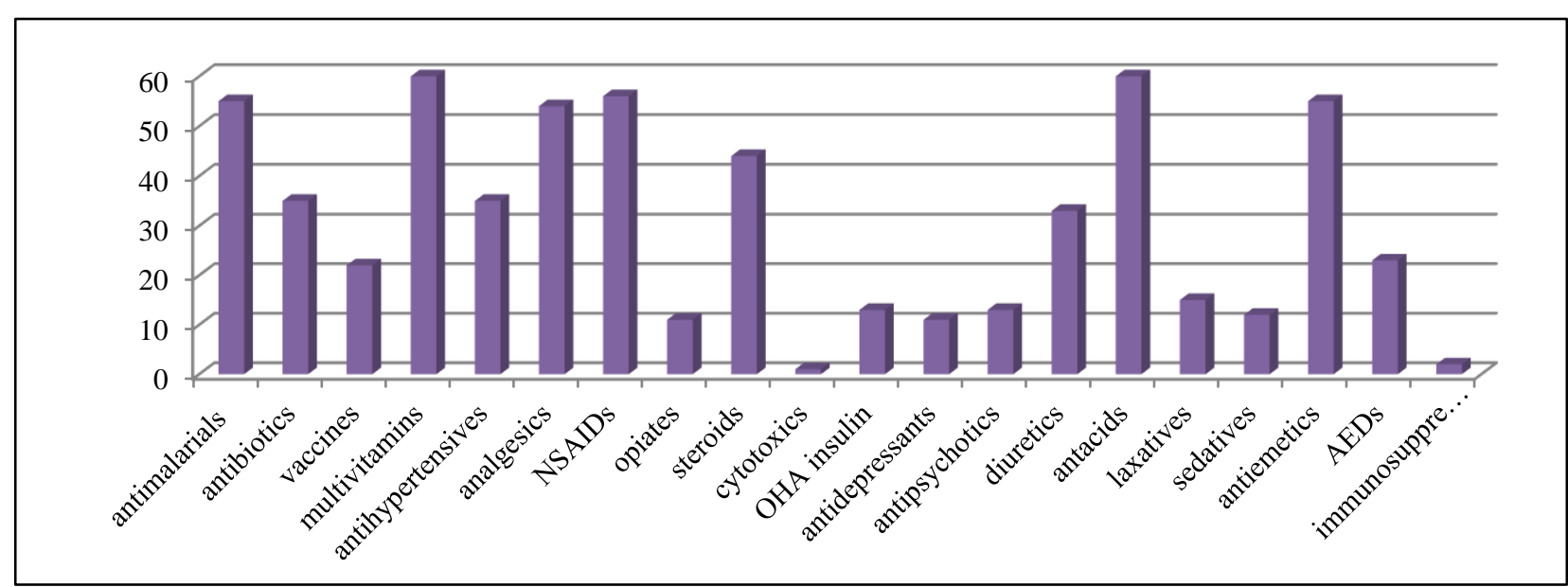

Figure 3: Drugs prescribed by interns without supervision in percentage.

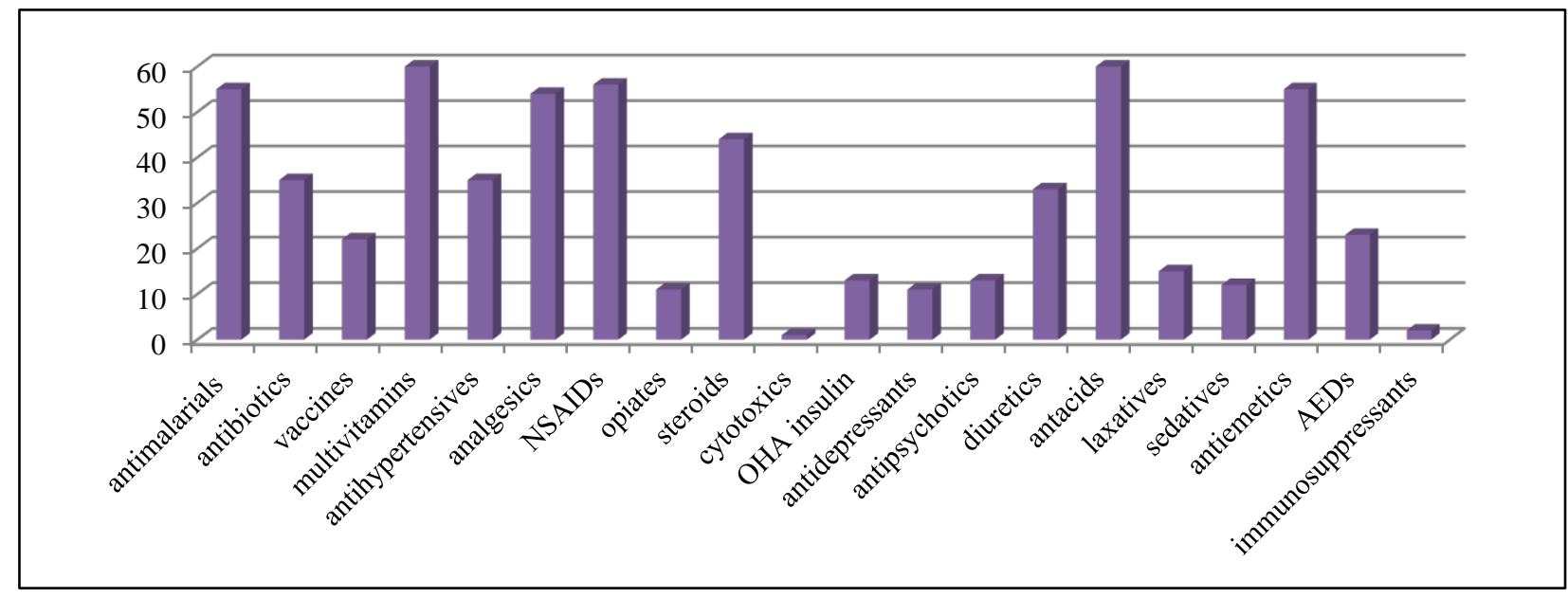

Figure 4: Prescription of drugs under supervision (for special cases) expressed in percentage. 
The various drugs which could be prescribed by the interns without the guidance of senior or faculty member is shown in Figure 3. Similarly, the interns required guidance/ advice from the senior or faculty member while prescribing different groups of drugs for special cases like elderly people, children, pregnant women or people with systemic diseases (renal /liver impairment).

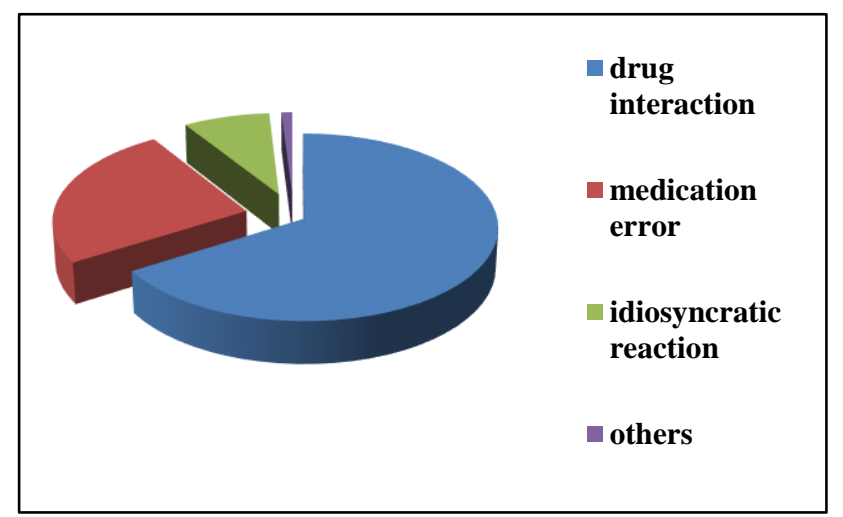

Figure 5: Reasons for adverse drug reaction expressed in percentage.

Out of 107 respondents, $80 \%$ of the interns felt that while prescribing safety of the drug was very important; $34 \%$ considered efficacy of drug as important; $40 \%$ considered cost (pharmacoeconomy) as important factor and 5\% of respondents felt that tolerance (or) resistance, age factors, life style factors, patient compliance, adverse drug reaction and age related dosage, combination of drugs should also be considered while prescribing.

Regarding adverse drug reaction, $90 \%$ of individuals were aware of adverse drug reaction. $47 \%$ had seen different types of adverse drug reaction during their internship period and $45 \%$ had seen during their training period. Figure 5 shows the reasons for adverse drug reaction as suggested by interns.

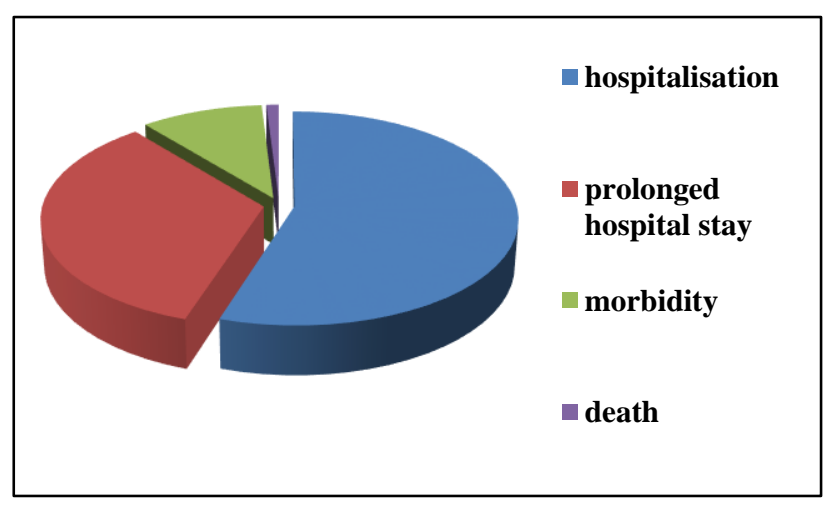

Figure 6: Consequences of adverse drug reaction according to interns in percentage.

Figure 6 shows the various consequences of adverse drug reaction according to the interns. $80 \%$ interns felt that adverse drug reaction was avoidable or predictable as per their knowledge. 90\% considered that adverse drug reaction could be prevented with improved knowledge and training. Percentage of the interns who reported or not reported adverse drug reaction is shown in Figure 7. Out of $22 \%$ who reported adverse drug reaction, $25 \%$ had reported it to head of the department, $5 \%$ to senior faculties in the department and $23 \%$ to adverse drug reaction monitoring committee in the hospital.

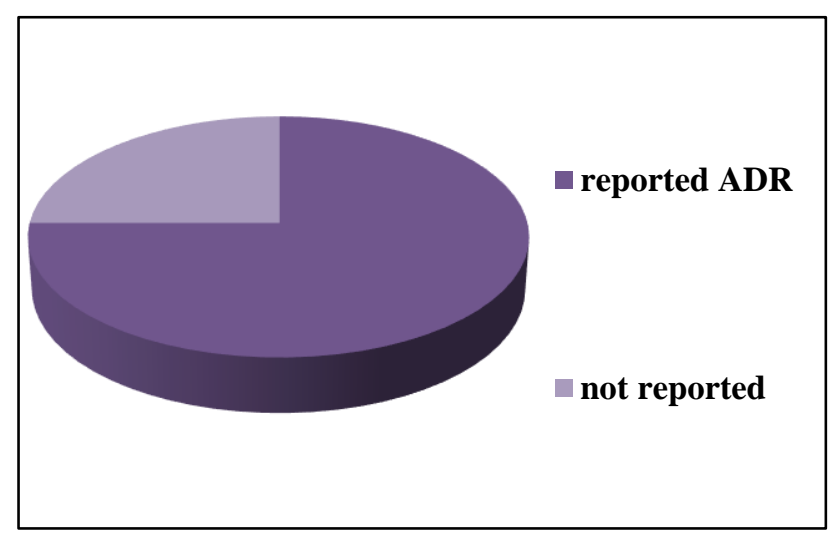

Figure 7: Percentage of interns who reported adverse drug reaction.

Out of 107 respondents, 67 interns felt that they would avoid adverse drug reaction using their undergraduate knowledge. Before prescribing the drug, $74 \%$ of the respondents had the habit of checking information about the drug profile and the main sources were CIMS / MIMS / refRx etc $(50 \%)$, text book of Pharmacology- Tripathi $(50 \%)$, drug information literature slips given along with drug (4\%) and Washington manual (1\%). Though majority of respondents had knowledge about adverse drug reaction and its consequences, more than $50 \%$ of the interns felt that CPT training should be improvised in following areas like adverse drug reaction (31\%), dosage (20\%), emergency medication $(20 \%)$, pediatric medication $(18 \%)$, therapeutic drug monitoring (9\%), selection of antibiotics (19\%), drug dosage $(7 \%)$, insulin dose calculation (10\%), antihypertensive (4\%), drug interaction (4\%), drug combination $(3 \%)$, dosage calculation $(5 \%)$, vaccination $(5 \%)$, route of administration (2\%), poisoning $(5 \%)$, pharmacodynamics of drug $(2 \%)$ and cytotoxic drugs $(1 \%)$, drugs with narrow therapeutic margin/window $(0.5 \%)$.

\section{DISCUSSION}

Gaining knowledge and implementing the same in clinical practice is the integral part of learning medicine. Learning CPT plays an important role in the development of rational and effective prescribing skills by the medical students. In our study majority of the respondents were aware of the $\mathrm{CPT}$ and rated their knowledge as average. However nearly half of the respondents were only satisfied with CPT teaching and feel confident about their rational prescribing skills whereas the rest were not which is quiet similar with a study done in other places where the main mass of the study population agreed that their knowledge of 
pharmacology and therapeutics is from average (40\%), good $(42 \%)$, and excellent $(7 \%)$ which is quite similar with findings of Nigeria. ${ }^{19}$ Prerna et al, also obtained similar result regarding students acknowledgement about prescription writing and rating of CPT. ${ }^{20}$ Kazeem et al, also conducted similar study on interns at Nigeria and obtained the similar result. ${ }^{21}$ However majority of them encountered problem during prescription which didn't correlate with previous data and problems mainly were calculation of doses, trade name of drugs and selection of drugs. One study conducted on drug dose calculating skills showed from junior and newly graduated doctors lagging behind in their dosage calculating skills and only half of interns had always double-checked their calculated doses. ${ }^{22}$ Similarly in another study conducted in Nepal suggested that training sessions on dosage calculation to be done at undergraduate level in Pharmacology as well as reinforcement of the same by various clinical departments had been insisted. ${ }^{23}$

Another important drawback at UG level is memorizing doses rather than calculating doses at pediatric level and this leads to more prescription error. So, training the undergraduate students on dose calculation and exposure to selection of drugs at clinical side is inevitable. This would prepare them for safe prescription later during their practice. Also, majority felt that clinical experience would improve their prescribing ability. But the lacunae at our setup are the enforcement of theoretical knowledge rather than practical teaching at undergraduate level. By exposing those to practical training and reassessment of their talents will bring confidence and practicing skills in them. CPT teaching could be made interesting by group discussion in clinical oriented pharmacology teaching rather than seminar according to one study. ${ }^{24}$ Drugs they managed to prescribe confidently without supervision were NSAIDS, vitamins and minerals, antihistamines, antacids, antibiotics, antiemetics, antiasthmatics, and inhalers; similar results were seen in a study conducted by Rehan et al. ${ }^{25}$ Antibiotics, non-steroidal anti-inflammatory drugs seem to be common cause of ADR at hospitals and common ADR being gastrointestinal bleeding due to drug therapy. ${ }^{26-28}$

Eighty-three percent of the study respondents feel retrospectively that Pharmacology and Therapeutics course should be improved to ensure rational prescribing. They have suggested some means for improvement and also identified a number of areas. This outcome is correspondingly quite comparable with a number of studies done in European countries and Canada. ${ }^{29-31}$ Although majority of the interns demanded they are competent enough to prescribe safely $(80 \%)$ and rationally (65\%). Furthermore, same study population has identified at least 12 areas they have specific problems which include chronic obstructive pulmonary disease, bronchial asthma, hypertension, diabetes mellitus, rational use of analgesics and antibiotics, paediatric doses, duration of drugs.

They also made a long list of drugs they are quite reluctant to prescribe. Also, the other drugs, where interns mentioned that they were confident to prescribe unsupervised, were also associated with several ADR. ${ }^{32}$ Prescribing errors were common with the interns due to number of factors during internship like lack of drug knowledge, increased workload, poor guidelines and inadequate supervision. ${ }^{33}$ Majority of interns were not confident to prescribe drugs for special categories like elderly, pediatric, pregnant women and patient with systemic illness. Hence more emphasis should be given at undergraduate level at these areas also. Only few were confident to prescribe NSAID and antibiotic. However, this confidence seemed to have gained because of repeated usage in clinical posting rather than knowledge about the drug. This also attributes to increasing number of prescription errors. According to majority, safety of patient was considered as prime importance whereas few mentioned the need to consider the cost and efficacy of the drug during prescription which is a good lead for rational prescription of drugs.

Despite limitation of this cross-sectional study, this study identified that pharmacology and therapeutics course curriculum is not enough to produce safe prescribers. Therefore, there is an urgent need of modifying pharmacology course curriculum.

\section{Funding: No funding sources}

Conflict of interest: None declared

Ethical approval: The study was approved by the Institutional Ethics Committee

\section{REFERENCES}

1. Mohan L, Chogtu B, Adiga S, Shenoy S, Bairy KL, Kishore A. Undergraduate medical students' perceptions regarding personal drug selection exercise. Int J Pharmacol Clin Sci. 2012;1(2):61-7.

2. Upadhyaya P, Seth V, Sharma M, Ahmed M, Moghe VV, Khan ZY, et al. Prescribing knowledge in the light of undergraduate clinical pharmacology and therapeutics teaching in India: views of first-year postgraduate students. Adv Med Educ Pract. 2012;3:47-53.

3. World Health Organization: National Drug Policy and Rational Drug Use. A model curriculum (draft) DAP/85,6. Action programme on essential drugs. Geneva World Health Organization 1985. Available at: http://www.who.int/iris/handle/10665/59217.

4. O'Shaughnessy L, Haq I, Maxwell S, Llewelyn M. Teaching of clinical pharmacology and therapeutics in UK medical schools: Current status in 2009. Br J Clin Pharmacol. 2010;70(1):143-8.

5. Leape LL, Bates DW, Cullen DJ, Cooper J, Demonaco HJ, Gallivan T, et al. Systems analysis of adverse drug events. ADE prevention study group. JAMA. 1995;274(1):35-43.

6. Barber N, Rawlins M, Franklin BD. Reducing prescribing error: competence, control, and culture. BMJ Quality Safety. 2003 Dec 1;12(suppl 1):i29-32. 
7. Kaushal R, Bates DW, Landrigan C, McKenna KJ, Clapp MD, Federico F, et al. Medication errors and adverse drug events in pediatric inpatients. JAMA. 2001 Apr 25;285(16):2114-20.

8. Barber N, Dean B. The incidence of medication errors and ways to reduce them. AVMA Med Legal J. 1998 Jul;4(4):103-6.

9. Weingart SN, Wilson RM, Gibberd RW, Harrison B. Epidemiology of medical error. BMJ. 2000;320(7237):774-7.

10. Bates DW, Cullen DJ, Laird N, Petersen LA, Small $\mathrm{SD}$, Servi D, et al. Incidence of adverse drug events and potential adverse drug events: implications for prevention. JAMA. 1995 Jul 5;274(1):29-34.

11. Palmer NO, Martin MV, Pealing R, Ireland RS, Roy $\mathrm{K}$, Smith A, et al. Antibiotic prescribing knowledge of National Health Service general dental practitioners in England and Scotland. J Antimicrob Chemotherapy. 2001 Feb 1;47(2):233-7.

12. Odusanya OO. Drug use indicators at a secondary health care facility in Lagos, Nigeria. J Community Med Primary Health Care. 2004;16(1):21-4.

13. Oshikoya KA, Chukwura HA, Ojo OI. Evaluation of outpatient paediatric drug prescriptions in a teaching hospital in Nigeria for rational prescribing. Paediatric and Perinatal Drug Therapy 2006; 7(4): 183-8.

14. Adebayo ET, Hussain NA. Pattern of prescription drug use in Nigerian army hospitals. Ann Afr Med 2010;9(3):152-8.

15. Otoom S, Culligan K, Al-Assoomi B, Al-Ansari T. Analysis of drug prescriptions in primary health care centres in Bahrain. East Mediterr Health J. 2010;16(5):511-5.

16. Chima IE, Obidiya OS, Abraham CVM. Evaluation of Drug Use and Patient Care Practices in a Referral Health Facility in Yenagoa, Bayelsa State, Nigeria. Continental J Pharmaceut Sci. 2012;6(1):10-6.

17. Goswami N, Gandhi A, Patel P, Dikshit R. An evaluation of knowledge, attitude and practices about prescribing fixed dose combinations among resident doctors. Perspect Clin Res. 2013;4(2):130-5.

18. Gawde SR, Shetty YC, Pawar DB. Knowledge, attitude, and practices toward ayurvedic medicine use among allopathic resident doctors: A cross-sectional study at a tertiary care hospital in India. Perspect Clin Res. 2013;4(3):175-80.

19. Oshikoya KA, Sebanjo IO, Amole OO. Interns' Knowledge of clinical pharmacology and therapeutics after undergraduate and on-going internship training in Nigeria. BMC Med Educ. 2009;9:50.

20. Upadhyaya P, Seth V, Sharma M, Ahmed M, Moghe VV, Khan ZY. Prescribing knowledge in the light of undergraduate clinical pharmacology and therapeutics teaching in India: views of first-year postgraduate students. Adv Med Educ Pract. 2012;3:47-53.
21. Oshikoya KA, Senbanjo IO, Amole OO. Interns' knowledge of clinical pharmacology and therapeutics after undergraduate and on-going internship training in Nigeria: a pilot study. BMC Medical Educ. 2009 Dec;9(1):50.

22. Nitya S, Mangaiarkkarasi A, Ali RM, Sawadkar SS. Intern's knowledge of clinical pharmacology and therapeutics at Puducherry: a cross-sectional study. Int J Basic Clin Pharmacol. 2013;2(5):622-8.

23. Rauniar GP, Das BP, Nagarani MA. Ability to calculate drugs doses. Indian J Pharmacol. 2000 Mar 1;32(2):129.

24. Garg A, Rataboli PV, Muchandi K. Students' opinion on the prevailing teaching methods in pharmacology and changes recommended. Indian J Pharmacol. 2004 May 1;36(3):155.

25. Rehan HS, Lal P. Drug prescribing pattern of interns at a government healthcare centre in northern India. Tropical Doctor. 2002 Jan;32(1):4-7.

26. Sriram S, Ghasemi A, Ramasamy R, Devi M, Balasubramanian R, Ravia TK, et al. Prevalence of ADRs at a private tertiary care hospital in south India. J Res Med Sci. 2011;16(1):16-25.

27. Pouyanne P, Haramburu F, Imbs JL, Bégaud B. Admissions to hospital caused by adverse drug reactions: cross sectional incidence study. BMJ. 2000 Apr 15;320(7241):1036.

28. Pirmohamed M, James S, Meakin S, Green C, Scott AK, Walley TJ, et al. Adverse drug reactions as cause of admission to hospital: prospective analysis of 18 820 patients. BMJ. 2004 Jul 1;329(7456):15-9.

29. Heaton A, Webb DJ, Maxwell SR. Undergraduate preparation for prescribing: the views of $2413 \mathrm{UK}$ medical students and recent graduates. $\mathrm{Br} \mathrm{J}$ Clin Pharmacol. 2008 Jul;66(1):128-34.

30. Likic R, Maxwell SR. Prevention of medication errors: teaching and training. Br J Clin Pharmacol. 2009 Jun 1;67(6):656-61.

31. Franklin BD, O’Grady K, Paschalides C, Utley M, Gallivan S, Jacklin A, et al. Providing feedback to hospital doctors about prescribing errors; a pilot study. Pharmacy World Sci. 2007 Jun 1;29(3):213-20.

32. Jamali AN, Aqil M, Alam MS, Pillai KK, Kapur P. A pharmacovigilance study on patients of bronchial asthma in a teaching hospital. J Pharm Bioallied Sci. 2010 Oct;2(4):333-6.

33. Coombes ID, Stowasser DA, Coombes JA, Mitchell C. Why do interns make prescribing errors? A qualitative study. Med J Aust. 2008 Jan 21;188(2):89-94.

Cite this article as: Gavimath NT, Chavan VR, Dixit R. Interns perception towards Pharmacology during clinical postings at RIMS, Raichur, India. Int J Basic Clin Pharmacol 2019;8:425-30. 